\title{
Hydromechanical behaviour of a volcanic ash
}

\author{
A. FERRARI*, J. EICHENBERGER* and L. LALOUI*
}

\begin{abstract}
This paper presents experimental analysis and numerical modelling aimed at improved understanding and prediction of the hydromechanical behaviour of volcanic ash at various states of saturation. Results from a comprehensive experimental programme are presented in order to characterise the response of the material in terms of matric suction and confining stress changes. The evolution of the yield stress at different suction levels has been quantified. The volumetric response with suction variations allowed the analysis of the collapse-upon-wetting behaviour. Water retention and permeability are also addressed. Tests results are used to calibrate a constitutive model based on the effective stress concept extended to partially saturated conditions. The ability of the model to reproduce and anticipate the ash behaviour is tested with an articulated stress path.
\end{abstract}

KEYWORDS: collapsed settlement; constitutive relations; laboratory tests; partial saturation; suction

\section{INTRODUCTION}

Volcanic ash soils cover approximately $0 \cdot 84 \%$ of the world's land surface (Leamy, 1984). Air-fall and colluvial deposits have variable thicknesses between $0.5 \mathrm{~m}$ and $7 \mathrm{~m}$, depending on the slope angle, and up to $50 \mathrm{~m}$ in morphological concavities and slope toes (Bilotta et al., 2005). Landslides in steep pyroclastic deposits induced by intense rainfall events have been observed around the world. These have caused severe destruction and loss of life. Examples are the Sarno landslide in Italy in 1998 (e.g. Crosta \& Dal Negro, 2003; Cascini et al., 2008) and the thousands of landslides in 1998 caused by Hurricane Mitch throughout much of Central America, with more than 9000 casualties (USAID, 1998).

The failure of volcanic deposit soil masses is often reported to turn into rapid flow slides or debris flows, with catastrophic consequences in the run-out zones (Picarelli et al., 2008). The physical mechanisms leading to sudden acceleration and the transition to flow-type behaviour, particularly in volcanic ashes, are still not fully understood. Several possible causes are detailed in the literature and summarised by Cascini et al. (2010), who cite as possible causes the volumetric collapse of loose unsaturated soils, static liquefaction in loose saturated soils, or local failures caused by transient, localised pore water pressures due to particular hydraulic boundary conditions and stratigraphic settings. In the beginning, the soils involved are mostly in a state of partial saturation, and they eventually saturate before failure or later in the failure stage, depending on the material properties and the morphological aspects of the slope. Any such changes in the degree of saturation are assumed to have a fundamental impact on the behaviour of volcanic ashes.

Recent studies have provided data for the seasonal suction measurements found in natural deposits of pyroclastic soils (e.g. Damiano et al., 2012), and criteria for early warning systems in volcanic ash slopes have recently been proposed by Eichenberger et al. (2013). However, systematic experimental programmes for the analysis of the geomechanical

Manuscript received 16 March 2013; revised manuscript accepted 23 July 2013. Published online ahead of print 19 September 2013.

Discussion on this paper closes on 1 May 2014, for further details see p. ii.

* Laboratory for Soil Mechanics, School of Architecture, Civil and Environmental Engineering, Ecole Polytechnique Fédérale de Lausanne, Lausanne, Switzerland. behaviour of volcanic ashes under partially saturated conditions are limited. Ng \& Chiu (2001) reported experiments for a compacted, unsaturated volcanic soil, and Sorbino \& Foresta (2002) analysed the hydraulic characteristics of pyroclastic soils. Olivares \& Picarelli (2003) and Olivares \& Damiano (2007) performed undrained triaxial tests and triaxial wetting tests to demonstrate the liquefaction potential of saturated volcanic ash, and the occurrence of undrained conditions at failure upon reaching a fully saturated state. The shear strength of undisturbed and remoulded volcanic ash in variably saturated states was investigated by Bilotta et al. (2005) using conventional direct shear tests with volcanic ash specimens at different levels of matric suction. Additionally, suction-controlled tests were carried out on undisturbed pyroclastic soils to highlight the effects of suction on the stiffness and the volumetric behaviour (Bilotta et al., 2006).

This paper presents the results from an experimental and numerical investigation aimed at analysing and predicting the geomechanical behaviour of a volcanic ash at various saturation states. The experimental programme was designed and carried out in order to collect evidence on the volumetric behaviour of the ash when subjected to changes in matric suction and vertical stress. The fabric of the material is first presented, and the technique for specimen preparation is discussed. The initial suction and water retention curves are then reported, and their dependence on the material porosity is analysed. The observation that the permeability is a function of the void ratio and degree of saturation is then discussed. Controlled-suction oedometric tests are presented in order to analyse the evolution of the preconsolidation pressure and the soil stiffness with suction, and to assess the position of the loading collapse yield limit.

For predicting the behaviour of the ash, the volume change response is interpreted in the light of a constitutive model for unsaturated soils. The constitutive model is presented prior to discussing the numerical simulations that were performed. The ability of the model to reproduce and anticipate the volcanic ash behaviour is tested by calibrating the model with some of the experimental results and validating it with an articulated stress path.

\section{CHARACTERISATION OF THE TESTED SOIL} Tested material and specimen preparation

The laboratory programme was carried out on a volcanic ash obtained from the sides of the Irazú Volcano in Costa 
Rica. The material was sampled using Shelby tubes to a depth of about $1.5 \mathrm{~m}$. The tested soil has a liquid limit $w_{1}=0.26$ and a plastic limit $w_{\mathrm{p}}=0 \cdot 20$. The natural water content for the collected samples was in the range $0 \cdot 22$ $0 \cdot 24$. The hygroscopic water content is 0.02 at the relative humidity and temperature of the laboratory (approximately $40 \%$ at $22^{\circ} \mathrm{C}$ ). The specific gravity is $G_{\mathrm{s}}=2 \cdot 61$, and the dry unit weight is in the range $9 \cdot 2-10 \cdot 2 \mathrm{kN} / \mathrm{m}^{3}$. The grain-size distribution presents a sand-size fraction of $48 \%$ and a siltsize fraction of $50 \%$. The soil is classified as a clayey-silty sand. In order to reproduce the average characteristics of the delivered samples, specimens for the hydromechanical tests (controlled-suction oedometric tests and triaxial tests) were prepared by moist-tamping at a water content of 0.24 and at a dry unit weight of $9.9 \mathrm{kN} / \mathrm{m}^{3}$ (average initial void ratio of $1 \cdot 58)$.

\section{Description of the fabric}

Figure 1(a) is an SEM image of an ash aggregate obtained from an undisturbed sample of the tested ash. The picture shows the typical fabric features of a collapsible soil, with grain-grain contacts encased with silt and clay particles (Collins \& McGown, 1974).

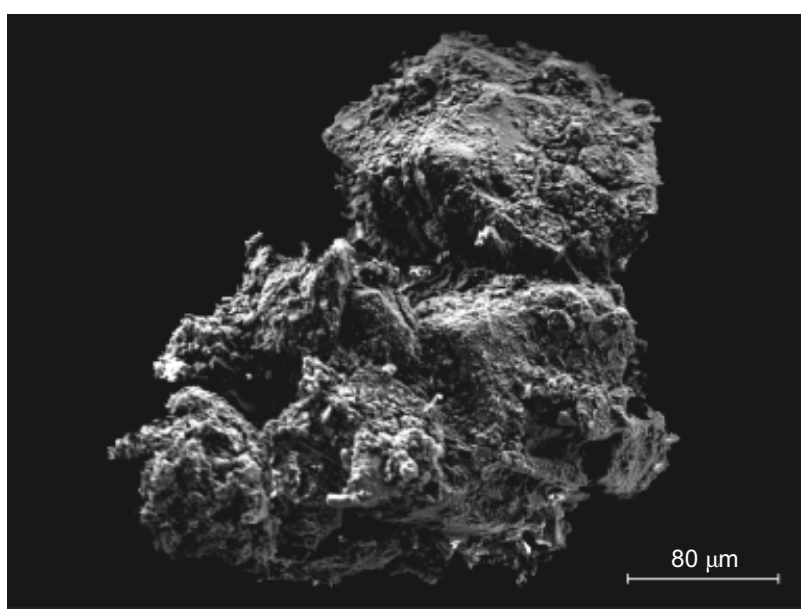

(a)

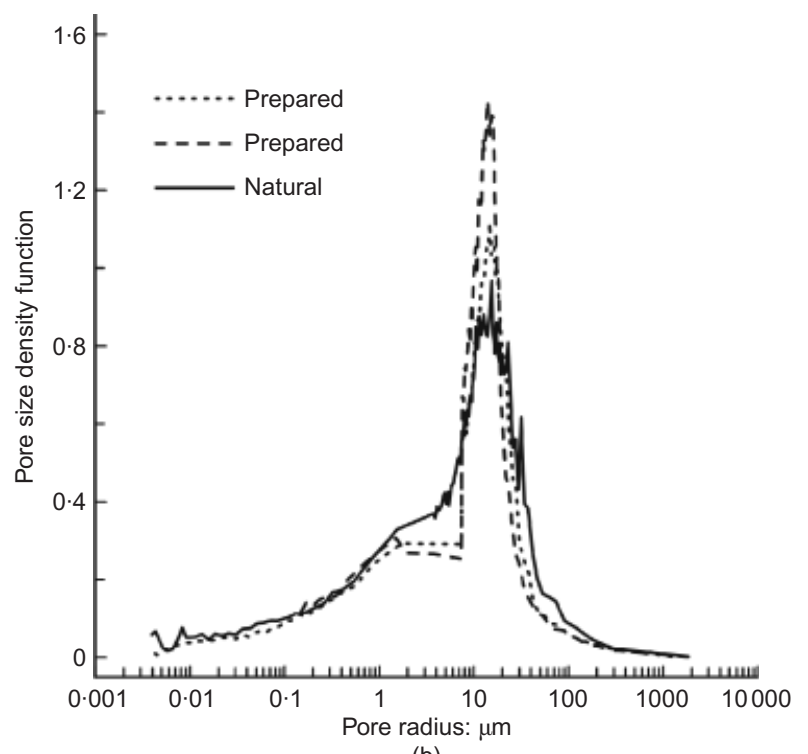

(b)

Fig. 1. Microstructural features of the tested volcanic ash: (a) SEM image of a natural ash aggregate; (b) results of MIP tests on natural and compacted specimens
Mercury intrusion porosimetry (MIP) was used to measure the pore size density (PSD) function of a natural sample of the volcanic ash, and of two specimens prepared at the target dry unit weight $\left(9 \cdot 9 \mathrm{kN} / \mathrm{m}^{3}\right)$. Specimens were trimmed and air-dried to remove the pore water. The analysis of the volumetric response upon drying of the statically compacted ash specimens showed that limited volume reductions were induced by drying (see below, under 'Controlled suction tests'). Therefore it could be assumed that the air-drying procedure did not induce significant changes in the soil structure. The MIP tests were performed in a Thermo Electron Corporations porosimeter, and attained a maximum intrusion pressure of $400 \mathrm{MPa}$, which corresponds to an entrance pore size dimension of about $2 \mathrm{~nm}$. The pressure was applied continuously, and the intrusion data (pressure and volume) were automatically recorded. To reach equilibrium, an appropriate pressure build-up rate and a long equalisation period were selected. The apparent pore sizes were determined by applying corrections for the compressibility changes of the various components of the equipment. Fig. 1(b) depicts the measured pore size density functions of the three specimens tested. The PSD is obtained according to the expression $\mathrm{PSD}=-\left[\Delta e_{\mathrm{Hg}} / \Delta(\log r)\right]$, where $r$ is the entrance pore radius and $e_{\mathrm{Hg}}$ represents the void ratio intruded at each increment of mercury pressure. The three specimens showed very similar PSDs, with dominant pore radii in the range $10-50 \mu \mathrm{m}$, which corresponds sufficiently well to the intergrain pores observed in Fig. 1(a). The small differences in the PSD could be explained by considering that the exact dry density is not known for the natural specimen. The similarity of the PSD functions demonstrated that the moist-tamping technique used to prepare the specimens resulted in a soil fabric similar to that of the natural material.

\section{Initial suction and water retention curve}

The initial matric suction was measured using contact filter paper. Leong et al. (2002) pointed out several factors affecting the method, and discussed existing calibration curves. In this study, an ad hoc calibration curve was determined on initially oven-dried Schleicher and Schuell No. 589 filter paper, in order to use the method for the measurement of low matric suction values. The initial ovendried condition ensured that there was an adequate transfer of water from the specimen to the paper during the measurement. The calibration was carried out by applying matric suction $(s)$ to the filter paper, in the range $20-100 \mathrm{kPa}$, by means of the axis-translation technique in a specially designed set-up. An equalisation time of 2 weeks was selected for both the calibration and the measurements. Fig. 2(a) shows the results of the calibration. The initial suction of the volcanic ash was measured on several specimens prepared at different water contents (in the range $0 \cdot 18-0 \cdot 25$ ) and dry unit weights $\left(8 \cdot 0,9 \cdot 8\right.$ and $\left.11 \cdot 4 \mathrm{kN} / \mathrm{m}^{3}\right)$, and these results are shown in Fig. 2(b). The plot allows an assessment of the initial suction in the range $20-45 \mathrm{kPa}$ for the natural water content of the samples in their 'as delivered' condition. It is worth noticing that, in the suction ranges considered, the dry unit weight has a marginal effect on the relationship between suction and water content.

Water retention curves were obtained using a controlledsuction pressure plate apparatus, employing the axistranslation technique at zero vertical stress. This method is associated with the matric suction component, in which the soil water potential is controlled predominantly by liquid phase transfer through an interface that is permeable to dissolved salts. The procedure involves translation of the reference air pressure by inducing an artificial increase in 


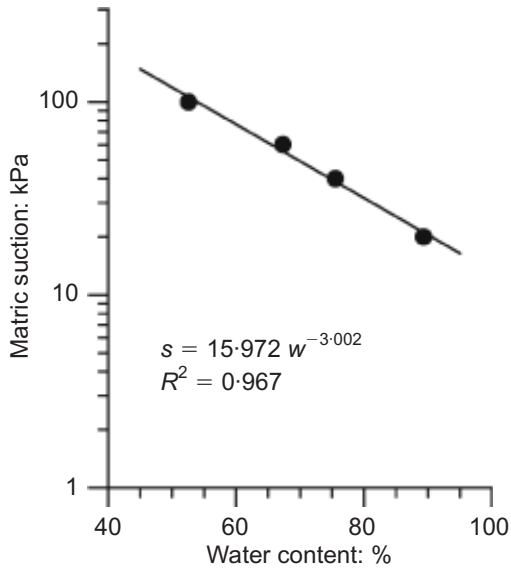

(a)

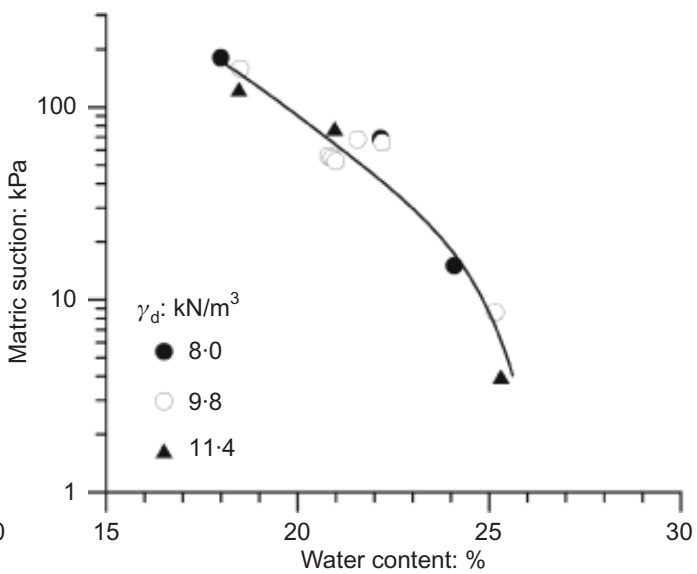

(b)

Fig. 2. Initial suction determination by contact Schleicher and Schuell No. 589 filter paper: (a) calibration of filter paper for matric suction measurement; (b) initial suction of volcanic ash as a function of water content for different values of dry unit weight

the atmospheric pressure in the apparatus. Water pressure was kept constant, and supplied through a pressure/volume controller by means of a high-air-entry value ceramic disc (bubbling pressure $0.5 \mathrm{MPa}$ ). The air pressure was applied in steps, and adjusted in order to impose suction values in the range $0-180 \mathrm{kPa}$. The specimens were prepared at different initial void ratios in confining rings $(35 \mathrm{~mm}$ in diameter and $4 \mathrm{~mm}$ high), and subsequently saturated. In a preliminary testing phase, the specimens were periodically weighed to assess the time required for a complete equalisation at the imposed suction; this was found to be 3 days. At the end of each suction step, the specimens were weighed and their volume measured. Solid weights were measured at the end of the test, and the water content and degree of saturation were back-calculated for each specimen. There was limited volumetric deformation during complete drying paths; in experiments on volcanic ash from the Vesuvian area, Sorbino \& Foresta (2002) observed similar behaviour during suction increments at low vertical stresses. The experimental results obtained for the suction and degree of saturation at three different values of the void ratio are depicted in Fig. 3. The experimental data obtained on the main drying and wetting paths are represented. The point corresponding to the hygroscopic water content is also represented (suction $\approx 80 \mathrm{MPa}$ ). It was observed that there was no significant dependence of

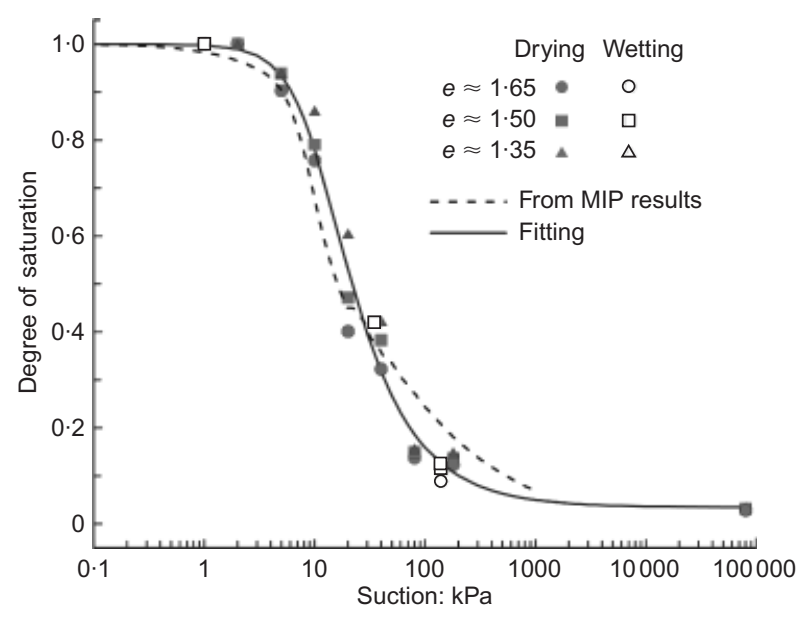

Fig. 3. Water retention behaviour of volcanic ash at different void ratios, and comparison with water retention curve based on MIP results the retention properties on the void ratio in the range considered. Also, there was no indication of any significant hysteretic effects during wetting and drying. The experimental points were fitted using the expression (van Genuchten, 1980)

$$
S_{\mathrm{r}}=S_{\mathrm{r}, \mathrm{res}}+\frac{1-S_{\mathrm{r}, \mathrm{res}}}{\left[1+(\alpha s)^{n}\right]^{m}}
$$

where $S_{\text {r,res }}$ is the residual degree of saturation (equal to $0.03) ; \alpha$ is a parameter related to the inverse of the air-entry value; and $n$ and $m$ are fitting parameters. Optimal curvefitting was obtained for the parameters $\alpha=0.91 \mathrm{~m}^{-1}$, $n=2 \cdot 19$ and $m=0 \cdot 42$. Information on the water retention properties of the volcanic ash was also gained from the mercury intrusion test. The injection of non-wetting mercury was assumed to be equivalent to the ejection of water from the pores by the non-wetting front advance of air (Romero et al., 1999). The void ratio not intruded by mercury was used to evaluate the degree of saturation corresponding to the equivalent imposed suction. The pressure of the mercury intrusion, $p$, and the suction, $s$, for the same pore diameter are related by the expression

$$
\begin{aligned}
s & =-\frac{\sigma_{\mathrm{w}} \cos \theta_{\mathrm{w}}}{\sigma_{\mathrm{Hg}} \cos \theta_{\mathrm{nw}}} p \\
& =0.196 p
\end{aligned}
$$

where $\sigma_{\mathrm{w}}$ and $\sigma_{\mathrm{Hg}}$ are the water and mercury surface tensions, $\theta_{\mathrm{w}}$ is the contact angle of the air/water interface $\left(0^{\circ}\right)$, and $\theta_{\text {nw }}$ is the non-wetting contact angle between the mercury and the soil grain (taken as equal to $140^{\circ}$ ). Fig. 3 presents the estimated water retention curve based on MIP data, which is compared with the curve obtained by the axis-translation technique. A good agreement is observed.

Both experimental methods suggest that the air-entry value of the material (the suction value at which the material starts to desaturate) is approximately $2 \mathrm{kPa}$. This value is assumed to be constant in the range of void ratios being considered.

\section{Permeability}

The permeability of the volcanic ash samples in a saturated condition $\left(k_{\mathrm{w}, \mathrm{sat}}\right)$ was measured by constant-head permeability tests carried out in a triaxial cell at different 
confining isotropic pressures. The applied radial stresses allowed good contact between the specimen and the latex membrane, and avoided preferential flow paths along the lateral surface of the specimen. The void ratio at the end of the consolidation phase was measured; in this way it was possible to establish the relationship between the coefficient of permeability and the void ratio.

The dependence of the permeability on the degree of saturation was assessed through back-analysis of the transient water exchange $\left(V_{\mathrm{w}}(t)\right)$ registered in the tests for the volumetric response with suction variation (see below, under 'Controlled-suction tests') (Kunze \& Kirkham, 1962; Romero et al., 2002),

$$
V_{\mathrm{w}}(t)=\left[1-\sum_{n=1}^{\infty} \frac{2 \exp \left(-\alpha_{n}^{2} D_{\mathrm{w}} t L^{2}\right)}{\alpha_{n}^{2}\left(A+\csc ^{2} \alpha_{n}\right)}\right] V_{0}
$$

where $V_{0}$ is the total inflow volume for a water pressure increment $\delta u_{\mathrm{w}} ; L$ is the soil height; $D_{\mathrm{w}}$ is the capillary diffusivity, which is dependent on the water permeability; $A$ is the ratio of the impedance of the ceramic disc to that of the soil $\left(A=k_{\mathrm{w}} t_{\mathrm{d}} / L k_{\mathrm{d}}\right.$, where $t_{\mathrm{d}}$ is the ceramic disc thickness, and $k_{\mathrm{d}}$ is its water permeability); and $\alpha_{n}$ is the $n$th solution of the equation $a \alpha_{n}=\cot \alpha_{n}$ (for $n=1,2, \ldots$ ). The ceramic disc had a thickness $t_{\mathrm{d}}=4.06 \mathrm{~mm}$ and a water permeability $k_{\mathrm{d}}=1.93 \times 10^{-10} \mathrm{~m} / \mathrm{s}$. In order to apply this method, a number of assumptions have to be satisfied: there should be no significant volume change during the suction change (true for the volcanic ash in drying paths); the water flow is isothermal and one-dimensional; the fluid is homogeneous and incompressible; and the flow of air in the porous medium is neglected, or considered as instantaneous. A non-linear, least-squares optimisation procedure was used to fit the test readings (time evolution of inflow data, $V_{\mathrm{w}}(t)$ ) to the predictions of the model, in order to obtain the $D_{\mathrm{w}}$ parameter. Water permeability $k_{\mathrm{w}}$ was calculated from the expression (Romero et al., 2002)

$$
k_{\mathrm{w}}=\frac{D_{\mathrm{w}} \gamma_{\mathrm{w}} V_{0}}{V \delta u_{\mathrm{w}}}
$$

where $V$ is the volume of the specimen, and $\gamma_{\mathrm{w}}$ is the specific weight of water. Water permeability values are depicted in Fig. 4 as a function of the degrees of saturation for different values of the void ratio. As a consequence of the experimental method, data were obtained only for the range of degree of saturation investigated with the controlled-suction oedometric tests. Experimental points are fitted using the expression

$$
k_{\mathrm{w}}\left(S_{\mathrm{r}}, e\right)=k_{\mathrm{w}, \mathrm{sat}} \cdot k_{\mathrm{w}, \mathrm{r}}
$$

where $k_{\mathrm{w}, \mathrm{r}}$ is the relative permeability function. $k_{\mathrm{w}, \mathrm{sat}}$ (in $\mathrm{m} / \mathrm{s}$ ) is expressed as a function of the void ratio as

$$
k_{\mathrm{w}, \mathrm{sat}}(e)=k_{\mathrm{w}, \mathrm{sat}}^{0} \cdot e^{c_{k}}
$$

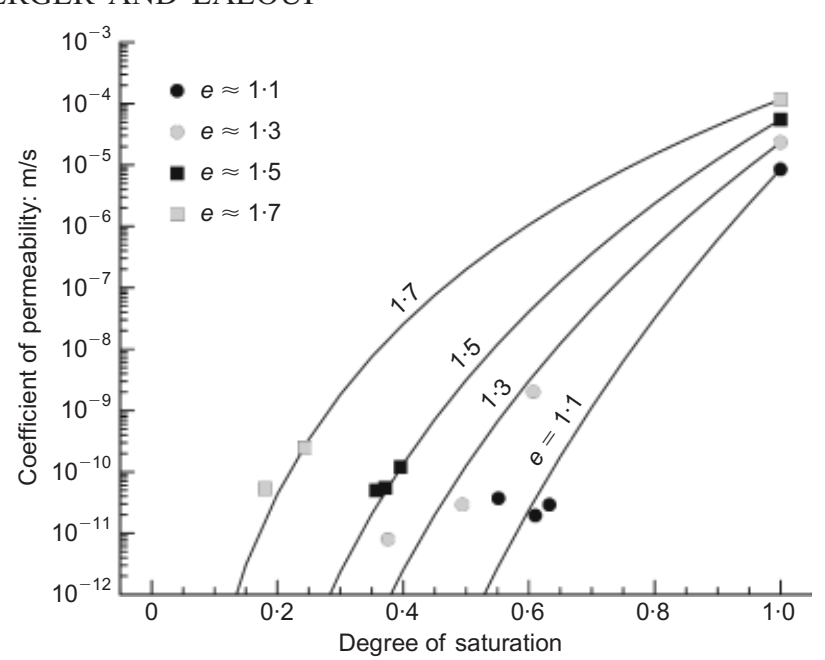

Fig. 4. Coefficient of permeability as a function of degree of saturation for different values of void ratio

where $k_{\mathrm{w}, \mathrm{sat}}^{0}$ is the saturated coefficient of permeability for a reference void ratio, and $c_{k}$ is a fitting parameter. The relative permeability function is expressed through the relationship (Brooks \& Corey, 1964)

$$
k_{\mathrm{w}, \mathrm{r}}\left(S_{\mathrm{r}}, e\right)=S_{\mathrm{r}}^{\lambda}
$$

where the dependence on the void ratio is accounted for with the exponent $\lambda$, and

$$
\lambda=c_{l} e+c_{m}
$$

where $c_{l}$ and $c_{m}$ are fitting parameters.

The fitting parameters for the permeability function and their values are summarised in Table 1.

\section{EXPERIMENTAL PROGRAMME \\ Controlled-suction oedometric tests}

Controlled-suction tests were planned and carried out in order to analyse the volumetric response of the unsaturated volcanic ash when it is subjected to variations in the degree of saturation.

Tests were carried out in a controlled-suction oedometer cell operating with the axis-translation technique on specimens with a diameter of $63.4 \mathrm{~mm}$ and a height of $16.30 \mathrm{~mm}$. Matric suction was controlled by keeping the air pressure constant and varying the water pressure applied to the specimen. Air pressure was controlled by means of a pressure-volume controller that pressurised the cell. The specimen rested on a ceramic disc (air-entry value of $0.5 \mathrm{MPa}$ ), through which the pore water pressure was controlled with a pressure-volume controller (operative accuracies for pressure and volume $1 \mathrm{kPa}$ and $10 \mathrm{~mm}^{3}$

Table 1. Parameters for water retention and permeability function

\begin{tabular}{l|c}
\hline Parameter & Value \\
\hline First VG parameter, $\alpha: \mathrm{m}^{-1}$ & $0 \cdot 91$ \\
Second VG parameter, $n$ & $2 \cdot 19$ \\
Third VG parameter, $m$ & $0 \cdot 42$ \\
Residual degree of saturation, $S_{\text {res }}$ & $0 \cdot 03$ \\
Coefficient of permeability in saturated conditions for reference void ratio, $k_{\mathrm{w}, \mathrm{sat}}^{0} \mathrm{~m} / \mathrm{s}$ & $4 \cdot 8 \times 10^{-6}$ \\
Fitting parameter for dependence of coefficient of permeability in saturated conditions on void ratio, $c_{k}$ & 6 \\
First fitting parameter for relative permeability function, $c_{m}$ & 53 \\
Second fitting parameter for relative permeability function, $c_{l}$ & $-25 \cdot 4$ \\
\hline
\end{tabular}


respectively). A coarse porous stone was in contact with the soil at the upper base. A vertical load was applied using a classical lever for oedometric cells, and vertical displacements were measured by means of an LVDT with a resolution of $1 \mu \mathrm{m}$. Pore water volume changes were monitored by means of the pressure-volume controller connected to the ceramic disc. Measurements of pore water volume changes were corrected to take into account air diffusion through and water evaporation from the ceramic disc (Airò Farulla \& Ferrari, 2005).

The stress paths followed in the controlled-suction apparatus are depicted in the plane of vertical net stress (difference between the total vertical stress and the applied air pressure) against suction in Fig. 5. Loading-unloading cycles at constant suction were performed to assess the evolution of the preconsolidation pressure and stiffness with suction (Ferrari et al., 2012). Suction reduction tests at constant vertical net stress were carried out to verify the position of the loading yield limit of the material.

After the reference air pressure translation, all the tested specimens were allowed to equalise to the initial suction values registered by the filter paper method (20-40 kPa); a low vertical net stress $(5-7 \mathrm{kPa})$ was applied in order to ensure contact between the loading ram and the specimen. In the loading and unloading oedometer tests the applied suction was maintained at $80 \mathrm{kPa}$ and $40 \mathrm{kPa}$ respectively (Figs 5(a) and 5(b)). Starting from the initial value, the vertical net stress was increased and reduced in steps, allowing the consolidation process induced by the load variation at each step to be stabilised. A third test (Fig. 5(c)) was carried out on a specimen dried at $120 \mathrm{kPa}$ of suction, then loaded at $118 \mathrm{kPa}$ of vertical net stress and wetted in steps up to a suction value of $1 \mathrm{kPa}$; the specimen was then dried at $80 \mathrm{kPa}$ of suction, loaded up to $470 \mathrm{kPa}$ and wetted a final time.

\section{Triaxial tests}

Complementary triaxial tests were performed in controlledstress-path triaxial systems, based on the classic Bishop \& Wesley design. Consolidated drained (CD) triaxial tests were performed under $20 \mathrm{kPa}, 50 \mathrm{kPa}$ and $100 \mathrm{kPa}$ initial confining isotropic effective stress conditions. During the consolidation phase, pore water volume changes were continuously measured in order to assess any changes in density. A deviatoric load was then applied in drained conditions. Before failure was reached, an unloading-reloading cycle of axial strain was performed in order to deduce the elastic properties of the material.

\section{TEST RESULTS}

\section{Controlled-suction tests}

Figure 6 depicts the results for the stress path shown in Fig. 5(a) in the planes suction against vertical net stress, void ratio against vertical net stress, suction against degree of saturation, and void ratio against degree of saturation. During the initial drying no significant deformation of the specimen was recorded, and only a limited reduction in the degree of saturation was observed (A-B) (in agreement with the retention curves reported in Fig. 3). The loading path $(B-C)$ at constant suction clearly defined the transition from a preyield to a post-yield behaviour. The unloading-reloading path allowed observation of the elastic response of the material $(\mathrm{C}-\mathrm{D})$, and confirmed the position of the normal compression line $(\mathrm{C}-\mathrm{E})$. As a consequence of the reduction in pore volume, an increase in the degree of saturation was obtained in the plane suction against degree of saturation; the path $\mathrm{B}-\mathrm{E}$ describes a scanning curve. The later wetting

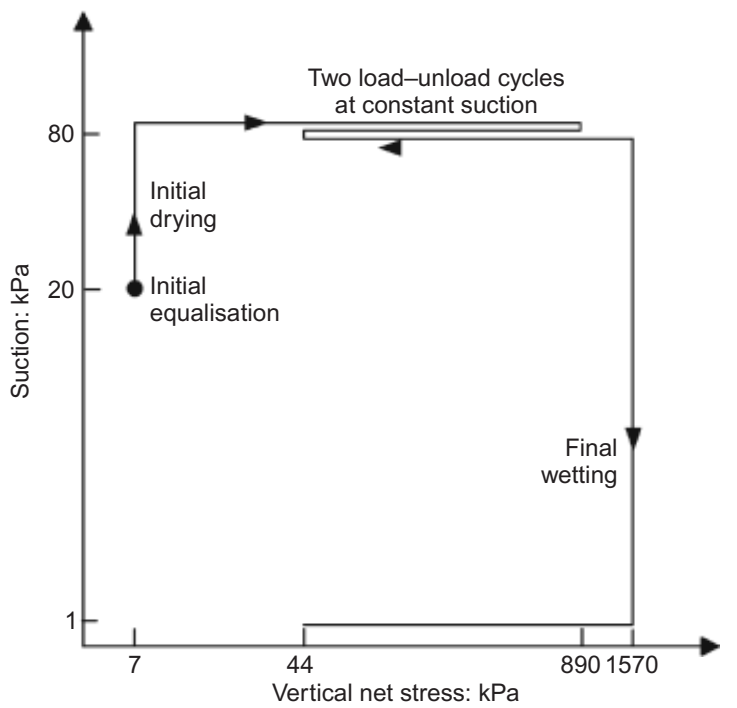

(a)

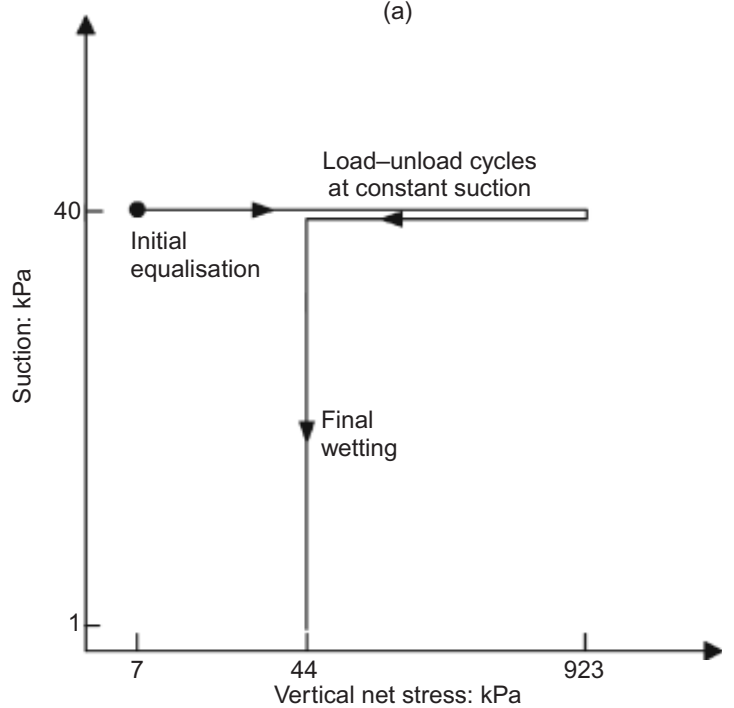

(b)

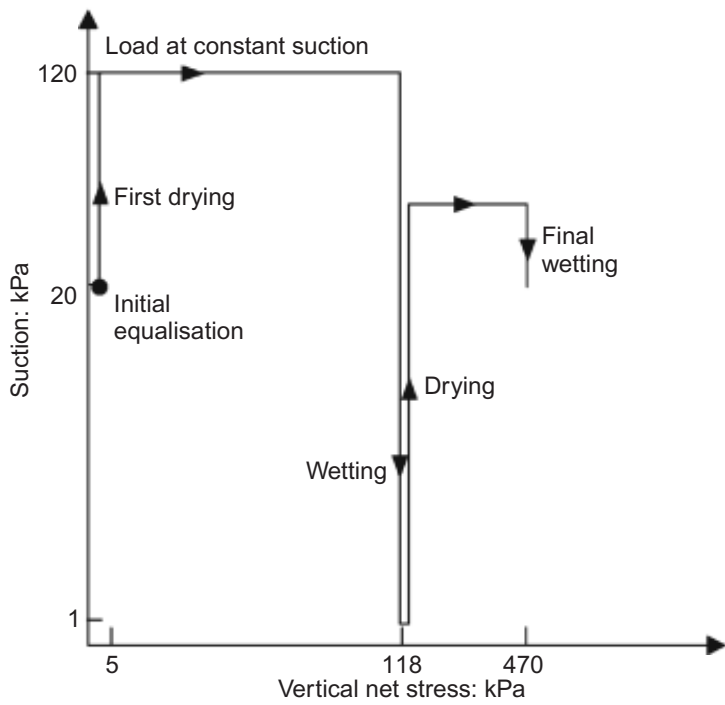

(c)

Fig. 5. Stress paths applied in controlled-suction oedometric tests

(E-F) induced a small reduction in the void ratio, while the degree of saturation increased up to 0.75 ; even if the settlement was quite limited, it is worth noting that the wetting of the material in a normally consolidated condition (E) induced 

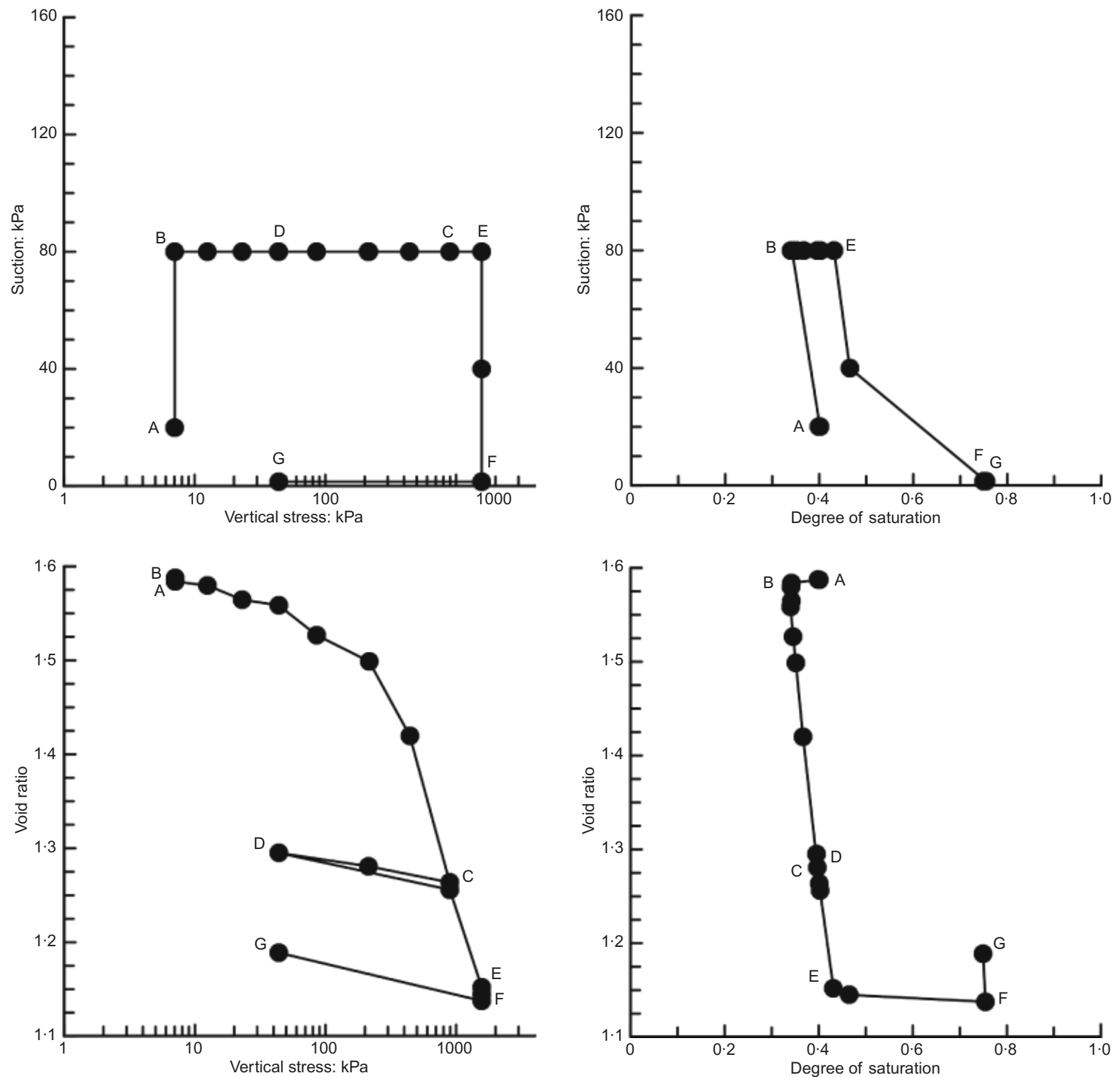

Fig. 6. Results for controlled-suction oedometric test following stress path in Fig. 5(a)

a rearrangement of the soil structure in the sense of a pore volume reduction. The limited settlement during wetting is a consequence of the previous load at $1570 \mathrm{kPa}(\mathrm{E})$, which induced significant cumulative volumetric plastic strains, and further limited any potential reduction in the pore volume. The final unloading at an imposed suction of zero followed a similar trend with respect to the unloading at a suction of $80 \mathrm{kPa}$; this suggested that the elastic response is independent of the applied suction.

Results for the stress path in Fig. 5(b) are reported in Fig. 7. The specimen was equalised at an initial suction of $40 \mathrm{kPa}$. The loading-unloading cycle $(\mathrm{A}-\mathrm{B}-\mathrm{C})$ allowed identification of the vertical net preconsolidation pressure at this suction value, which was approximately $110 \mathrm{kPa}$. During the loading phase $(\mathrm{A}-\mathrm{B})$, the degree of saturation increased from 0.39 to 0.58 ; in this case the change in the degree of saturation is related to the reduction of the pore volume, because no significant changes in the water content were recorded during the loading phase. In other words, the material was able to retain water during the loading, and no squeezing out of the pore water occurred. The reduction in pore volume seems to have shifted the retention curve of the material (the points $\mathrm{B}$ and $\mathrm{C}$ do not match the reference retention curve in Fig. 3); in other words, the void ratio reduction is responsible for a higher retention capacity of the material in terms of degree of saturation for a given suction (Salager et al., 2013). The wetting path C-D (suction from $40 \mathrm{kPa}$ to $0 \mathrm{kPa}$ ) induced a significant increase of the degree of saturation, which approached $90 \%$. The volumetric response during the wetting resulted in a slight increase of the void ratio; it is worth noting that, in this case, unlike the wetting performed in the stress path shown in Fig. 5 (a), the wetting of the specimen was performed in an overconsolidated condition (vertical net stress $44 \mathrm{kPa}$, maximum previous vertical net stress $923 \mathrm{kPa}$ ).

Figure 8 shows the results for the stress path shown in Fig. 5(c). In a similar manner as for the first stress path, the initial drying $(\mathrm{A}-\mathrm{B}$, up to $120 \mathrm{kPa}$ ) did not induce any significant variation in the void ratio. The loading $\mathrm{B}-\mathrm{C}$ compressed the soil, but the normal compression line was not reached. The stress path continued with progressive wetting in steps $(\mathrm{C}-\mathrm{E})$. In the first part $(\mathrm{C}-\mathrm{D})$ the suction changed from $120 \mathrm{kPa}$ to $40 \mathrm{kPa}$; as a consequence, the pore volume was unchanged, while the degree of saturation in- 

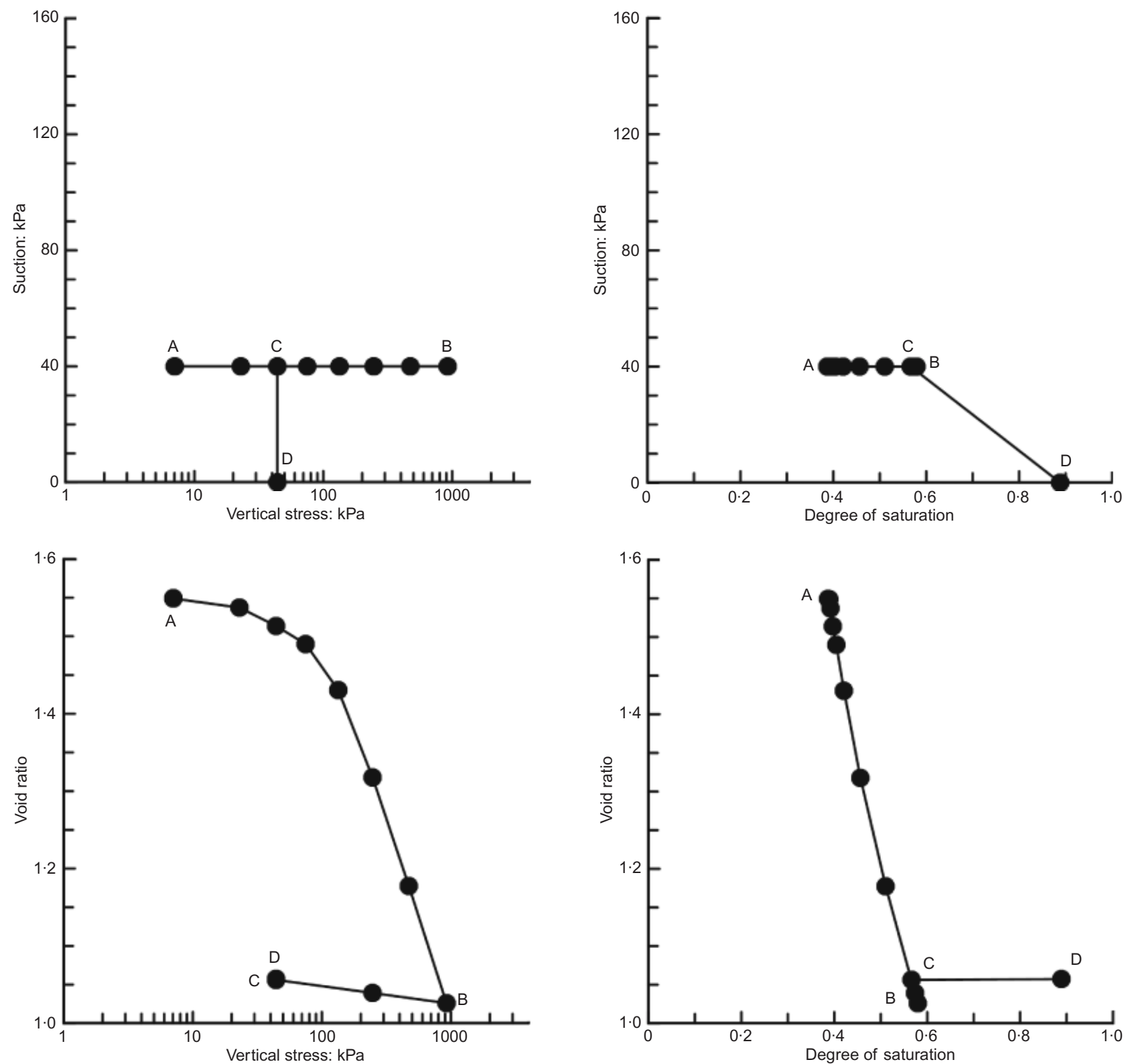

Fig. 7. Results for controlled-suction oedometric test following stress path in Fig. 5(b)

creased from 0.35 to $0 \cdot 39$ (in agreement with the retention curve in Fig. 3). In the following wetting step (D-E) the suction was reduced to $1 \mathrm{kPa}$, with a consequent increase in the degree of saturation. During this wetting a reduction in the void ratio was observed; this reduction of the pore volume is a result of the progressive disappearance of the menisci in the soil as the water fills the pores (increment of the degree of saturation). Subsequent drying did not induce changes in the void ratio $(\mathrm{E}-\mathrm{F})$, while the response in terms of the degree of saturation showed a significant reversibility in the wetting-drying episode. This last observation confirms that the hysteretic features in the retention properties are quite limited for the range of void ratios considered. The next loading $(\mathrm{F}-\mathrm{G})$ seemed to take place in a normally consolidated condition. The final wetting produced no significant volume variation; however, it is worth noting that the small change in the void ratio was in effect a volume reduction. This confirms the tendency of the material to collapse when it is wetted under normally consolidated conditions. The volume reduction is due to the strong decrease in the void ratio that occurred during the previous loadings.
Triaxial tests

The volumetric behaviour observed upon shearing of the volcanic ash is reported in Fig. 9, where the results of the deviatoric parts of the triaxial tests are shown. From the triaxial plane deviatoric stress against mean effective stress, a shearing resistance angle of $35.5^{\circ}$ was deduced. The specimens showed monotonic contractive behaviour along the triaxial loading path, with higher values of volumetric deformation when the initial confining stresses were larger. As seen in the plane of deviator stress against axial deformation $\left(\varepsilon_{\mathrm{a}}\right)$, the test specimens displayed a strong plastic hardening at low values of axial deformation, followed by a steady increase in deviatoric stress with axial strains increasing up to the testing limit of $20 \%$.

\section{MODELLING OF TEST RESULTS AND \\ INTERPRETATION}

ACMEG-s: a constitutive model for unsaturated soils

This section reviews the main concepts of the elastoplastic constitutive model that is used for modelling the hydromechanical behaviour of the unsaturated volcanic ash. 

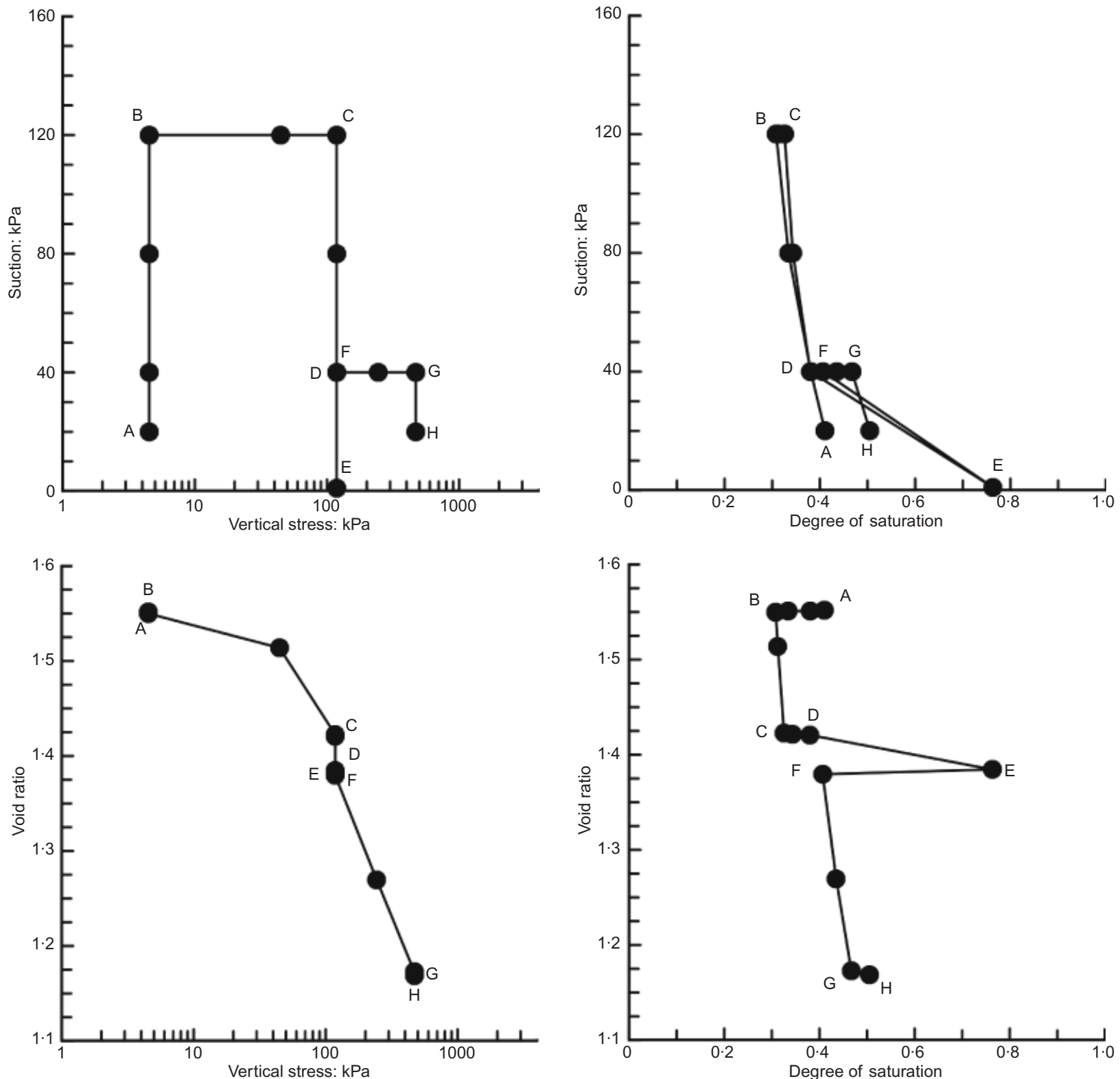

Fig. 8. Results for controlled-suction oedometric test following stress path in Fig. 5(c)

The Advanced Constitutive Model for Environmental Geomechanics (ACMEG-s) (Nuth \& Laloui, 2007; Nuth \& Laloui, 2008) is a Cam-Clay-type elasto-plastic model, and is based on Hujeux's model (Hujeux, 1979). The increment of strain, $\mathrm{d} \varepsilon_{i j}$, is decomposed into

$$
\mathrm{d} \varepsilon_{i j}=\mathrm{d} \varepsilon_{i j}^{\mathrm{e}}+\mathrm{d} \varepsilon_{i j}^{\mathrm{p}}
$$

where $\mathrm{d} \varepsilon_{i j}^{\mathrm{e}}$ is the elastic strain increment, and $\mathrm{d} \varepsilon_{i j}^{\mathrm{p}}$ is the plastic strain increment. The elastic deformation can be expressed as

$$
\mathrm{d} \varepsilon_{i j}^{\mathrm{e}}=C_{i j k l} \cdot \mathrm{d} \sigma_{k l}^{\prime}
$$

The tensor $C_{i j k l}$ is the mechanical elastic tensor, and is composed of non-linear elastic moduli. The elastic strain increment $\mathrm{d} \varepsilon_{i j}^{\mathrm{e}}$ can be decomposed into volumetric and deviatoric increments, given as

$$
\begin{aligned}
\mathrm{d} \varepsilon_{\mathrm{v}}^{\mathrm{e}} & =\frac{\mathrm{d} p^{\prime}}{K_{\mathrm{ref}}\left(p^{\prime} / p_{\text {ref }}^{\prime}\right)^{n^{\mathrm{e}}}} \\
\mathrm{d} \varepsilon_{\mathrm{d}}^{\mathrm{e}} & =\frac{\mathrm{d} q}{3 G_{\text {ref }}\left(p^{\prime} / p_{\text {ref }}^{\prime}\right)^{n^{\mathrm{e}}}}
\end{aligned}
$$

The material parameters $K_{\text {ref }}, G_{\text {ref }}$ and $n^{\mathrm{e}}$ are respectively the bulk elastic modulus at a reference mean stress $p_{\text {ref }}^{\prime}$, the reference shear elastic modulus at $p_{\text {ref }}^{\prime}$, and the non-linearity exponent, $n^{\mathrm{e}} \in[0,1] . \sigma_{k l}^{\prime}$ is the effective stress, given by

$$
\sigma_{k l}^{\prime}=\left(\sigma_{k l}-u_{\mathrm{a}} \delta_{k l}\right)+S_{\mathrm{r}}\left(u_{\mathrm{a}}-u_{\mathrm{w}}\right) \delta_{k l}
$$

where $\sigma_{k l}$ is the total stress, $u_{\mathrm{a}}$ is the pore air pressure, $u_{\mathrm{w}}$ is the pore water pressure, $S_{\mathrm{r}}$ is the degree of saturation, and $\delta_{k l}$ is Kronecker's delta. The difference $\left(u_{\mathrm{a}}-u_{\mathrm{w}}\right)$ represents the matric suction $(s)$. The product between the degree of saturation and the matric suction is computed by means of the retention curve (equation (1)).

The critical state line is defined in the plane of deviatoric stress $q$ against mean effective stress $p^{\prime}$, with a slope $M$. The slope of the critical state line in the plane volumetric 


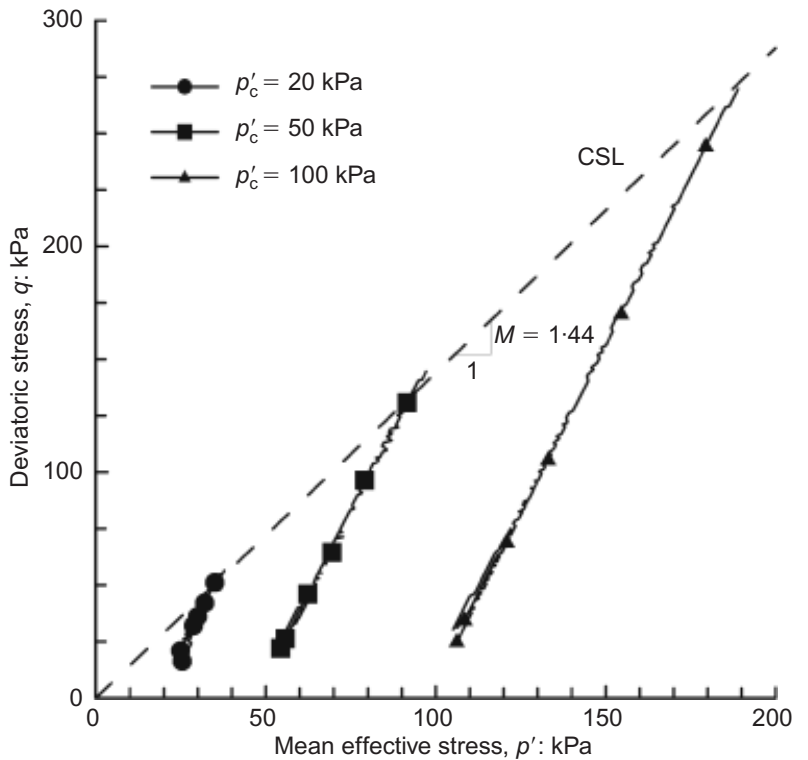

(a)

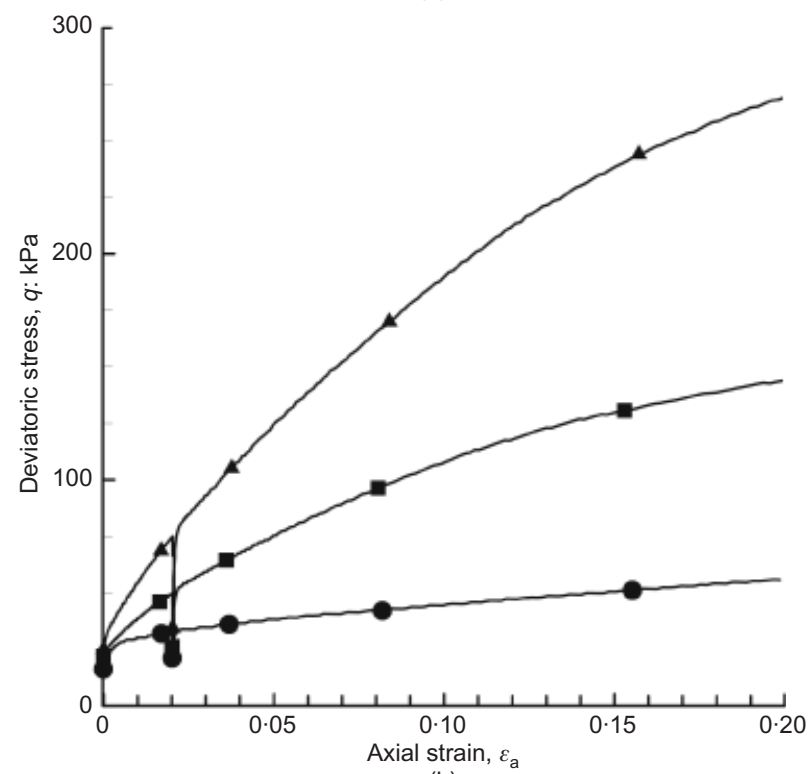

(b)

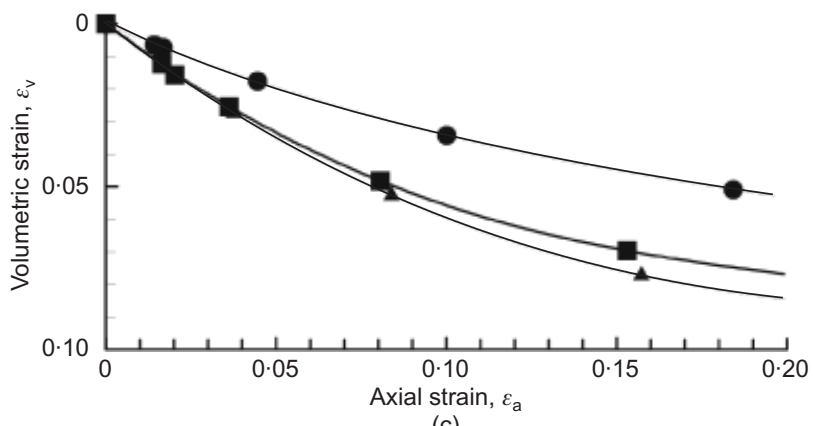

(c)

Fig. 9. Results of the shearing phases of three CD triaxial tests on volcanic ash specimens in terms of: (a) deviatoric stress against mean effective stress; (b) deviatoric stress against axial deformation; (c) volumetric strain against axial strain

plastic strain against mean effective stress $\left(\varepsilon_{\mathrm{v}}^{\mathrm{p}}-\ln p^{\prime}\right)$ is $\beta$, and $p_{\mathrm{CR} 0}^{\prime}$ is the initial critical state pressure

$$
\ln \frac{p_{\mathrm{CR}}^{\prime}}{p_{\mathrm{CR} 0}^{\prime}}=\beta \varepsilon_{\mathrm{v}}^{\mathrm{p}}
$$

In the ACMEG-s model, the plastic irreversible strain increment $\mathrm{d} \varepsilon_{i j}^{\mathrm{p}}$ is induced by two coupled dissipative pro- cesses: an isotropic and a deviatoric plastic mechanism. The yield limits of each mechanism, bounding the elastic domain in the effective stress space, can be written as

$$
\begin{aligned}
& \tilde{f}_{\text {iso }}=p^{\prime}-r_{\text {iso }} \cdot d \cdot p_{\mathrm{CR}}^{\prime} \\
& \tilde{f}_{\mathrm{dev}}=q-M p^{\prime}\left(1-b \ln \frac{p^{\prime}}{p_{\mathrm{CR}}^{\prime}}\right) r_{\mathrm{dev}}
\end{aligned}
$$

where $p_{\mathrm{CR}}^{\prime}$ is the critical state pressure; $d, b, r_{\text {iso }}$ and $r_{\mathrm{dev}}$ are material parameters; and $\varepsilon_{\mathrm{v}}^{\mathrm{p}}$ and $\varepsilon_{\mathrm{d}}^{\mathrm{p}}$ are respectively the volumetric and the deviatoric plastic strains. The critical state pressure can be related to the preconsolidation pressure $p_{\mathrm{c}}^{\prime}$ using the material parameter $d$ according to

$$
p_{\mathrm{c}}^{\prime}=d \cdot p_{\mathrm{CR}}^{\prime}
$$

Using the space of triaxial stress variables $q$ and $p^{\prime}$, the elastic domain is enclosed by an ellipsoidal surface, which is cut by the isotropic yield limit (Fig. 10). By adding the suction $s$ as a third axis of the space, it can be shown that the elastic domain gets larger with suction. This accounts for the fact that a dryer material will have higher strength and stiffness. The contribution of the capillary effects to the mechanical behaviour of the material is accounted for by introducing a dependence of the preconsolidation pressure $p_{\mathrm{c}}^{\prime}$ on the level of suction $s$. For the volcanic ash being considered, the expression used was

$$
p_{\mathrm{c}}^{\prime}=z \begin{cases}p_{\mathrm{c} 0}^{\prime} & \text { if } s \leqslant s_{\mathrm{e}} \\ p_{\mathrm{c} 0}^{\prime}\left[1+\gamma_{\mathrm{s}}\left[\log \left(s / s_{\mathrm{e}}\right)\right]^{n_{\mathrm{LC}}}\right] & \text { if } s \geqslant s_{\mathrm{e}}\end{cases}
$$

where $p_{\mathrm{c} 0}^{\prime}$ is the initial preconsolidation pressure at zero suction, $s_{\mathrm{e}}$ is the air-entry value, and $\gamma_{\mathrm{s}}$ and $n_{\mathrm{LC}}$ are material parameters. This equation defines the loading collapse (LC) curve. The LC curve predicts a constant preconsolidation pressure when the soil remains saturated. When suction becomes higher than the air-entry value and the soil starts to dry, the preconsolidation pressure increases as a consequence of the formation of menisci within the soil skeleton.

\section{Model parameters determination}

The calibration for the mechanical ACMEG-s model is done iteratively using two of the constant-suction oedometer tests and the saturated triaxial tests.

The evolution of preconsolidation pressure with suction has to be determined first in order to define the limits of the

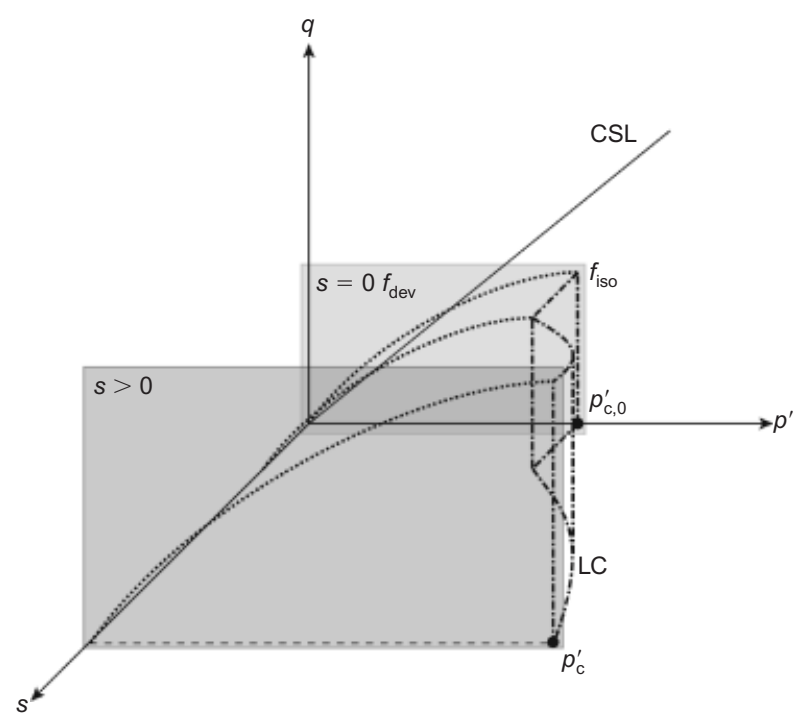

Fig. 10. Yield surfaces of ACMEG-s model in $p^{\prime}-q-s$ space 
elastic domain. Trial runs of the model in oedometric conditions, in conjunction with a graphical interpretation of the oedometric curves, permitted the determination of preconsolidation pressures at different levels of matric suction. The mean effective stress at the critical state, $p_{\mathrm{CR}}^{\prime}$, hereafter designated as the critical pressure, and the preconsolidation pressure $p_{\mathrm{c}}^{\prime}$ are proportionally related to each other through the parameter $d$. The value of $d$ (equation (16)) was determined by considering the normal compression line (NCL) and the critical state line (CSL) in the $\varepsilon_{\mathrm{V}}-\log p^{\prime}$ plane (Fig. 11). The NCL and the CSL were obtained from three triaxial tests (with samples confined at 20,50 and $100 \mathrm{kPa}$ ) analysing the isotropic compression phase and the shearing phase respectively. A value of $d=2$ was determined. The resulting values for the critical pressures at different levels of matric suction are listed in Table 2.

The increase of the elastic domain with suction is accounted for through the use of a loading collapse curve (LC), for which equation (17) was found to be the best fit for the target preconsolidation pressures at various suction levels. The fitted values for the parameters were $\gamma_{\mathrm{s}}=0.54$, and $n_{\mathrm{LC}}=5.34 ; p_{\mathrm{c} 0}^{\prime}=38 \mathrm{kPa}$ is the initial preconsolidation pressure under saturated conditions, and $s_{\mathrm{e}}=2 \mathrm{kPa}$ is the air-entry value (see above under 'Initial suction and water retention curve'). The loading collapse curve is plotted in Fig. 12.

The elastic stiffness parameters $K_{\text {ref }}$ and $G_{\text {ref }}$ are calibrated on the initial loading branch in the $\varepsilon_{\mathrm{v}}-\ln \sigma_{\mathrm{v}}^{\prime}$ plane of the saturated oedometer test and the $q-\varepsilon_{\mathrm{a}}$ plane of the triaxial tests. The reference pressure $p_{\text {ref }}^{\prime}$ is equal to $1 \mathrm{MPa}$ in the ACMEG-s routine. The effect of the elastic exponent $n^{\mathrm{e}}$ on the non-linear elastic response is particularly visible at higher stress levels, and is calibrated with the aim of getting a good representation of the unloading-loading branches in the oedometer tests. Using a reference bulk modulus $K_{\text {ref }}=60 \mathrm{MPa}$, a shear modulus $G_{\text {ref }}=4.2 \mathrm{MPa}$, and an elastic exponent $n^{\mathrm{e}}=0 \cdot 8$, the predicted results for non-zero suction levels are in good agreement with the experimental data (Fig. 13)

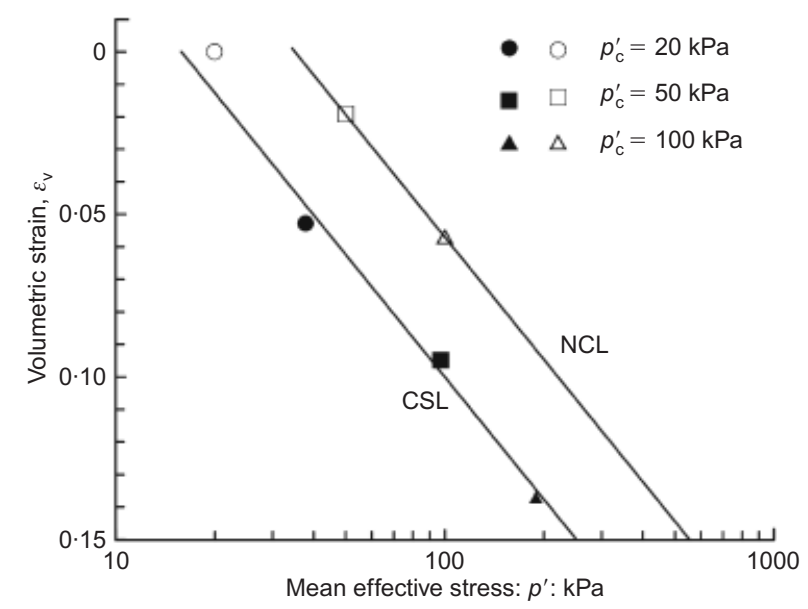

Fig. 11. Determination of parameter $d$ in consolidation plane

Table 2. Critical pressures $p_{C R}^{\prime}$ at different levels of matric suction

\begin{tabular}{l|c}
\hline Test & $p_{\mathrm{CR}}^{\prime}: \mathrm{kPa}$ \\
\hline Saturated & 19 \\
$40 \mathrm{kPa}$ matric suction & 60 \\
$80 \mathrm{kPa}$ matric suction & 146 \\
\hline
\end{tabular}

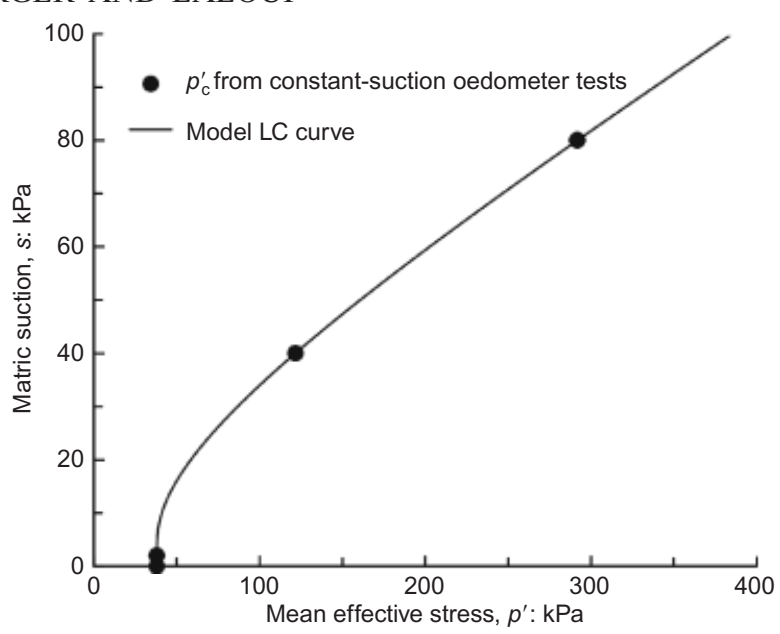

Fig. 12. Loading collapse (LC) curve

The plastic compressibility $\beta$ is exclusively calibrated on the basis of the saturated one-dimensional compression test. A value of $\beta=10$ was found to be the best fit. Since the experimental data do not show any stiffening or softening tendency with suction, the same plastic compressibility coefficient is used for all suction levels.

Again with reference to the oedometric curves, the plasticity parameters $r_{\mathrm{iso}}^{\mathrm{e}}$ and $c$ are used to define the degree of mobilisation of the isotropic mechanism, and allow smoothing of the transition between the elastic and elasto-plastic parts of the curve. More precisely, the initial degree of mobilisation $r_{\text {iso }}^{\mathrm{e}}$ defines the point at which the plastic strains start to develop during loading. The parameter $c$ governs the evolution of the degree of mobilisation of the isotropic mechanism as a function of volumetric plastic strains due to activity of the isotropic mechanism. Fitting values for these parameters are $c=10^{-4}$ and $r_{\text {iso }}^{\mathrm{e}}=0 \cdot 3$.

Shear strength and dilatancy parameters have to be calibrated in order to describe the deviatoric stress-strain behaviour of the volcanic ash. The elastic part has already been dealt with in conjunction with the saturated oedometer test. A friction angle $\phi^{\prime}=35.5^{\circ}$ at critical state is derived from the slope $M$ in the conventional $q-p^{\prime}$ plane from three

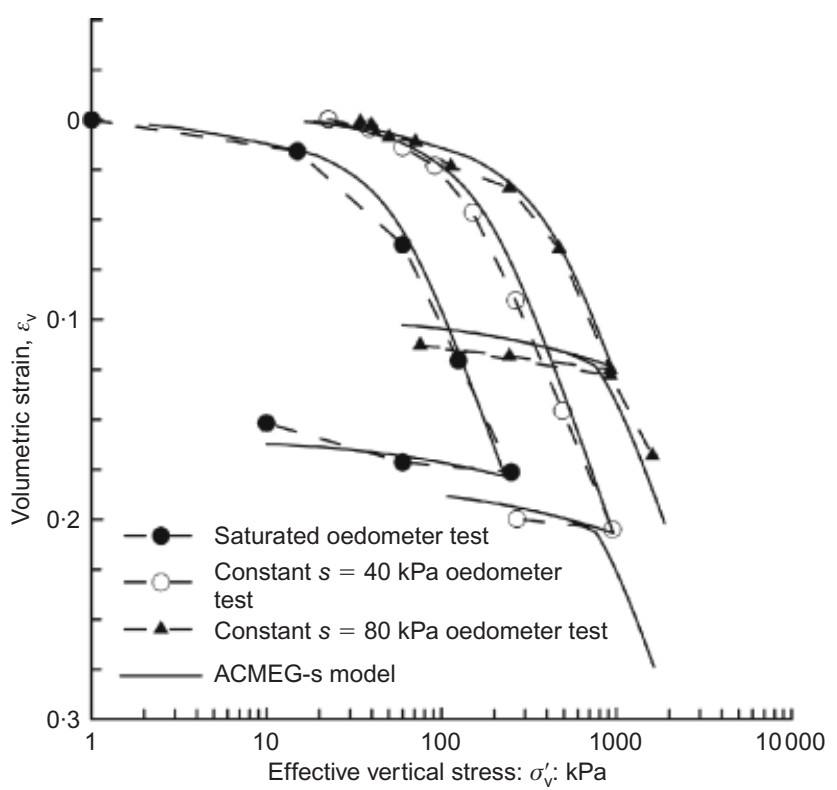

Fig. 13. Comparison between constant-suction oedometer tests and calibrated ACMEG-s model 
triaxial tests at initial confining stresses of 20,50 and $100 \mathrm{kPa}$ (Fig. 14(a)).

As an analogue to the isotropic part, the degree of mobilisation of the deviatoric plastic mechanism needs to be calibrated by means of parameters $r_{\mathrm{dev}}^{\mathrm{e}}$ and $a$. A value of $a=0.005$ is defined in order to reproduce the strong hard-

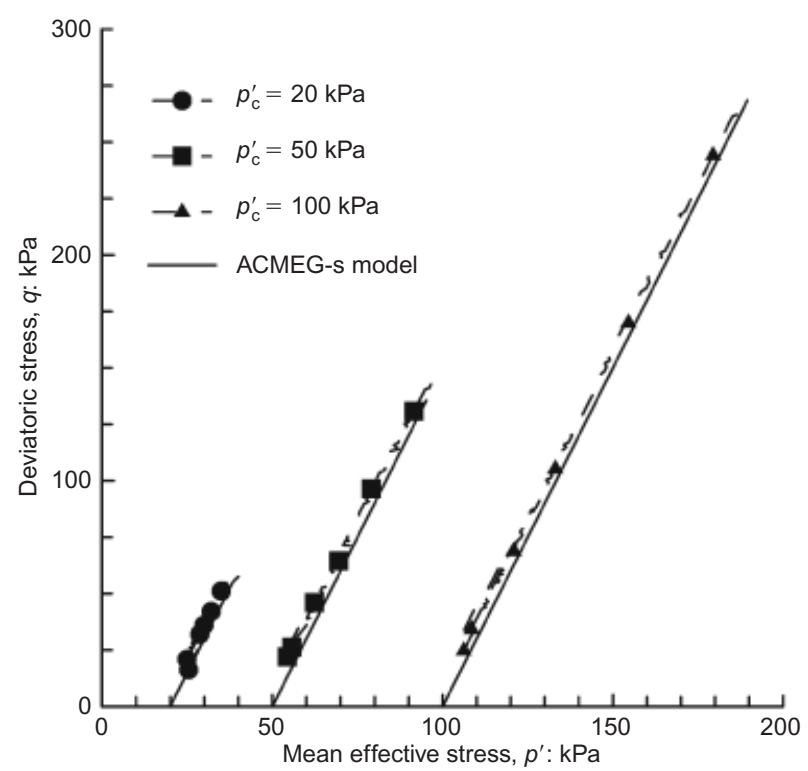

(a)

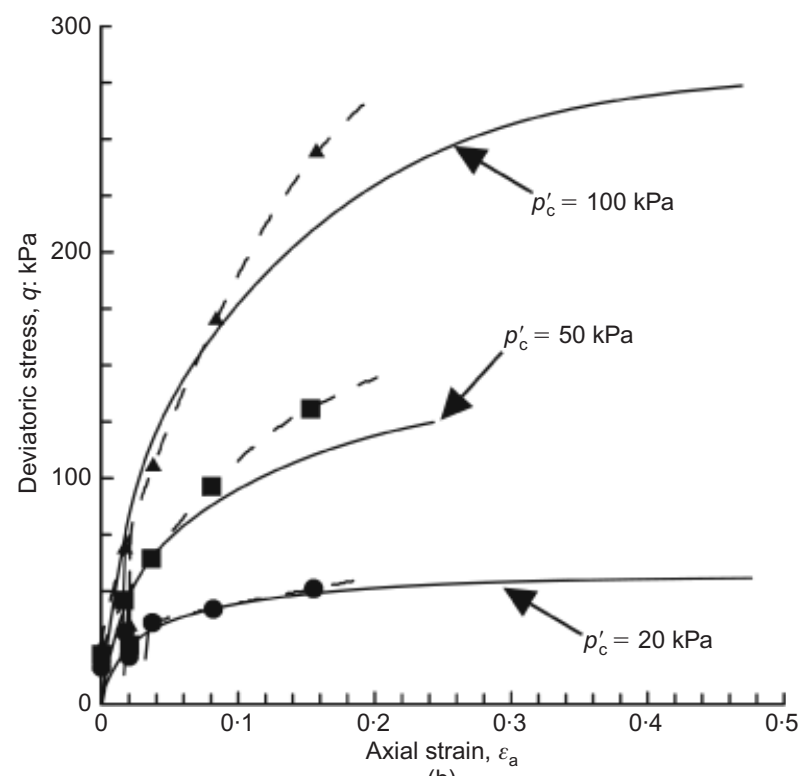

(b)

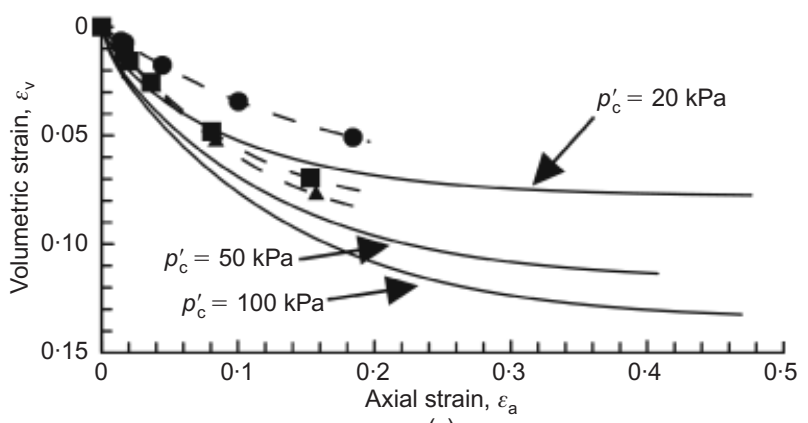

(c)

Fig. 14. Laboratory and ACMEG-s model response of volcanic soil under triaxial loading conditions of 20,50 and $100 \mathrm{kPa}$ initial confining stress: (a) deviatoric stress against mean effective stress; (b) deviatoric stress against axial strain; (c) volumetric strain against axial strain ening observed at low axial deformation (Fig. 14(b)). The initial degree of mobilisation $r_{\mathrm{dev}}^{\mathrm{e}}$ is set to a low value equal to 0.25 to better reproduce the gradual increase in volumetric plastic strains with axial deformation (Fig. 14(c)). The plasticity parameter $b$ that defines the shape of the deviatoric yield surface influences the amount of volumetric strain and mobilised shear strength generated for a given axial deformation, as well as the peak strength of the frictional material at high relative density. In the case of loose volcanic air-fall deposits, it is reasonable to assume a low value for the parameter $b$, as is usually the case for sands. Since the ash has not been tested so far along stress paths involving high stress ratios $\eta=q / p^{\prime}$ (e.g. constant shear drained stress path, CSD) a best-fit value of $b=0.5$ is used.

\section{Simulation of a hydromechanical stress path for model validation}

An articulated loading programme, as presented in Fig. 5(c), was simulated with the calibrated model to test its capacity to correctly predict volumetric deformations induced by wetting-drying cycles and mechanical loading stress paths. Fig. 15(a) depicts the changes in the effective vertical stress along the stress path. Void ratio changes are plotted as a function of the effective vertical stress in Fig. 15(b). In general, the volume changes are well reproduced by the numerical model.

When considering the different loading steps, it is observed that the contraction of the sample during the initial drying and mechanical loading phases is identical in the laboratory experiments and the model. Good agreement with the experimental results is also achieved for the subsequent wetting phase, which includes two distinct parts: the first shows a decrease in the effective vertical stress at a more or less constant void ratio, and the second indicates a clear decrease in the void ratio with a slight decrease in the effective vertical stress.

In fact, as shown in Fig. 16(a), the simulated stress path of the model is at first within the elastic domain (see steps $\mathrm{a}-\mathrm{c} 1$ ), before it encounters the yield locus of the isotropic plastic mechanism during the first wetting phase (step c2). As a consequence, the model generates volumetric plastic strains in terms of contraction. The resulting decrease in the void ratio is clearly seen in Fig. 16(b), where the void ratio is plotted against the matric suction. The model predicts a similar amount of collapse upon wetting as observed in the experiments. Following the wetting phase, both the model and the experimental results demonstrate that the soil undergoes elastic deformations as it is dried until $40 \mathrm{kPa}$ of matric suction is reached (step d). Then the soil is again loaded mechanically up to $500 \mathrm{kPa}$ of effective vertical stress (step e). For this loading step, the experimental results show strong variations in the void ratio, which are only partly reproduced by the model, because the simulated stress path remains within the elastic domain up to approximately $200 \mathrm{kPa}$ of mean effective stress (Fig. 16(a)). However, as shown in Fig. 15(b), the variations in the void ratio for a given change in effective vertical stress are the same in the experiment and the numerical simulation within the plastic range. In a final stage, the normally consolidated soil is wetted again and produces a slight collapse (step f). The test is stopped when $20 \mathrm{kPa}$ of matric suction is reached. The constitutive model produces too much pore collapse during the second wetting phase at high effective vertical stresses (Figs 15(b) and 16(b)). If one considers the level of effective vertical stresses in shallow ash covers (i.e. in the first few metres of soil, where shallow landslides usually occur), this inaccuracy is not of concern for the model simulations. 


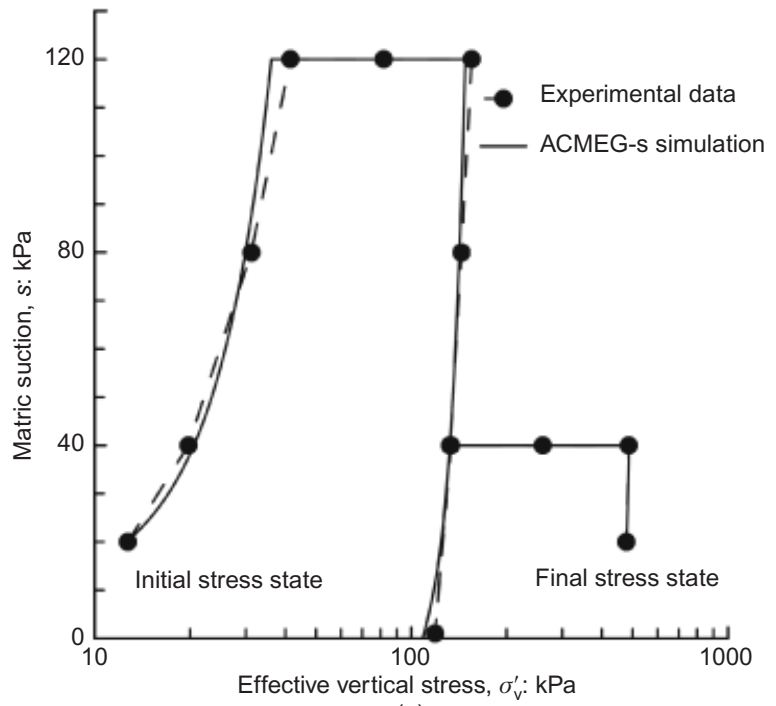

(a)

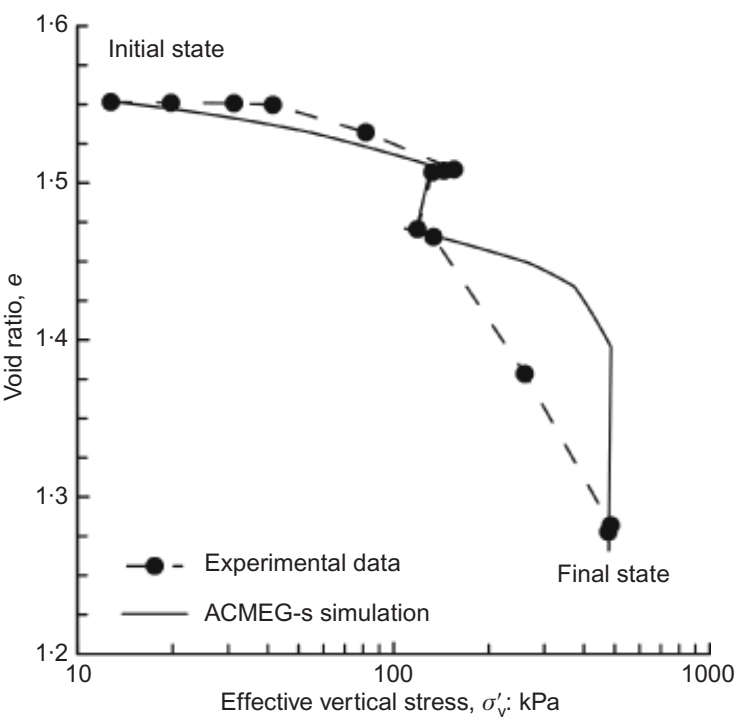

(b)

Fig. 15. (a) Experimental and simulated stress paths for drying and wetting cycles with intermittent mechanical loading in suction-vertical effective stress plane; (b) void ratio changes along experimental and simulated stress paths

\section{SUMMARY AND CONCLUSIONS}

Despite the relative abundance of volcanic ash cover, and the risks related to rainfall-induced landslides in steep pyroclastic deposits, few studies are available in which the geomechanical behaviour of ash is analysed, particularly the consideration of how changes in the degree of saturation can affect slope stability.

This paper aimed to combine experimental results and numerical modelling to reproduce and predict the behaviour of a volcanic ash at various states of saturation. A comprehensive experimental programme was carried out in order to characterise the hydromechanical response of the material by conducting controlled-suction oedometric tests. Overall, the volcanic ash tested presented typical features of collapsible silty sands. The evolution of the yield stress at different suction levels was quantified. The volumetric response to suction variations allowed assessment of the behaviour of the ash in overconsolidated states, and showed limited shrinkage upon drying and collapse upon wetting. The study of the water retention behaviour showed negligible hysteretic features and insignificant dependence on the dry density for the

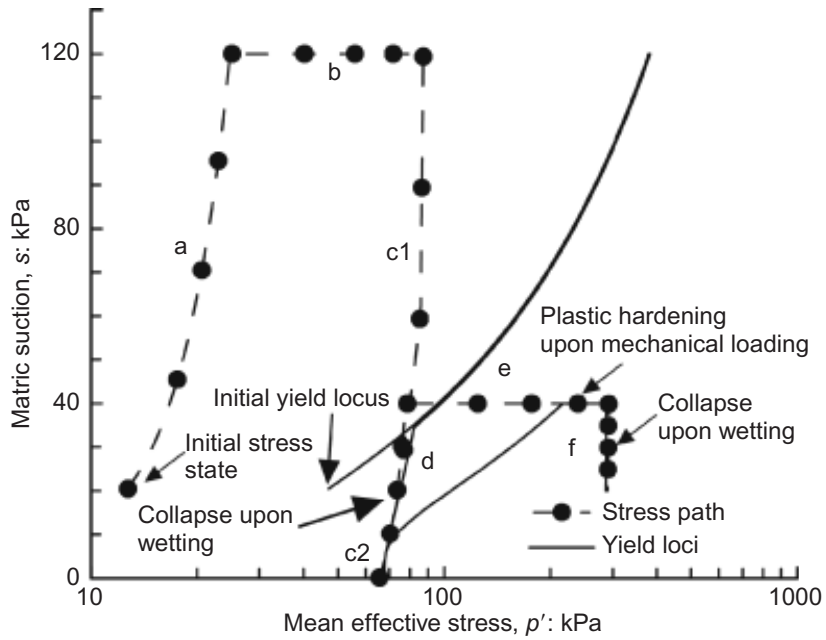

(a)

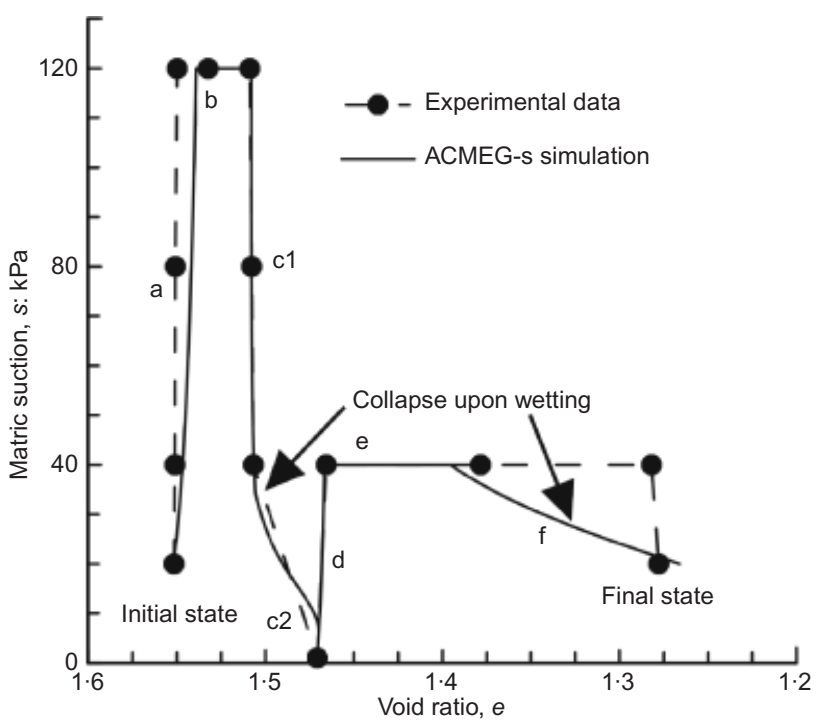

(b)

Fig. 16. (a) Experimental and simulated stress paths and yield loci for drying and wetting cycles with intermittent mechanical loading in suction-mean effective stress plane; (b) the resulting void ratio changes

void ratios considered. The permeability under partially saturated conditions was evaluated by back-analysis of the transient pore water exchanges measured in the controlledsuction tests; an equation has been provided that expresses the permeability as a function of the void ratio and the degree of saturation.

The experimental test results allowed the calibration of an advanced constitutive model based on the effective stress concept extended to partially saturated conditions. In order to predict the ash behaviour, the volume change response is interpreted in the light of a constitutive model for unsaturated soils. The constitutive model is presented prior to discussing the actual numerical simulations performed. The ability of the model to reproduce and anticipate the ash behaviour is tested by calibrating the model with some of the collected experimental results and validating it with an articulated stress path.

\section{NOTATION}

$A$ ratio of impedance of ceramic disc to impedance of soil

a ACMEG-s model parameter 
$b$ ACMEG-s model parameter defining shape of yield surface

ACMEG-s model parameter

fitting parameter for water permeability

$c_{l}$ fitting parameter for water permeability

$c_{m}$ fitting parameter for water permeability

$D_{\mathrm{w}}$ capillary diffusivity

$d$ ACMEG-s model parameter

void ratio

$e_{\mathrm{Hg}}$ void ratio intruded at each increment of mercury pressure

$\tilde{f}_{\text {dev }}$

$f_{\text {iso }}$

$G_{\text {ref }}$

$G_{\mathrm{s}}$

$K_{\text {ref }}$

deviatoric yield limit function

isotropic yield limit function

reference shear elastic modulus

specific gravity

bulk elastic modulus

ceramic disc water permeability

water permeability

relative permeability function

permeability in saturated conditions

saturated coefficient of permeability for reference void ratio soil specimen height

slope of critical state line in $q-p$ plane

fitting parameter

fitting parameter

non-linearity exponent

material parameter

pressure of mercury intrusion

mean effective stress

mean effective stress increment

preconsolidation pressure

nitial preconsolidation pressure at zero suction

critical state pressure

nitial critical state pressure

reference mean effective stress

deviatoric stress

deviatoric stress increment

entrance pore radius

ACMEG-s model parameter

initial degree of mobilisation

material parameter

initial degree of mobilisation

degree of saturation

residual degree of saturation

matric suction

air-entry value

time

ceramic disc thickness

air pressure

water pressure

volume of specimen

total inflow volume

ransient water exchange

liquid limit

plastic limit

parameter related to inverse of air-entry value

$n$th solution of equation $a \alpha_{n}=\cot \alpha_{n}$ (for $n=1,2, \ldots$ )

slope of critical state line in $\varepsilon_{\mathrm{v}}^{\mathrm{p}}-\ln p$ plane

material parameter

specific weight of water

Kronecker's delta

axial strain

deviatoric plastic strain

ncrement of deviatoric elastic strain

volumetric strain

volumetric plastic strain

increment of strain tensor

increment of elastic strain tensor

increment of plastic strain tensor

increment of volumetric elastic strain

stress ratio

non-wetting contact angle between mercury and soil

contact angle of air/water interface

fitting parameter

mercury surface tension

water surface tension $\sigma_{k l}$ total stress tensor

$\sigma_{k l}^{\prime} \quad$ effective stress tensor

$\mathrm{d} \sigma_{k l}^{\prime}$ increment of effective stress tensor

$\sigma_{\mathrm{v}}^{\prime} \quad$ vertical effective stress

$\sigma_{1}$ axial stress

$\sigma_{1}^{\prime}$ axial effective stress

$\sigma_{3}$ radial stress

$\sigma_{3}^{\prime} \quad$ radial effective stress

$\phi^{\prime}$ shear strength angle

\section{ACKNOWLEDGEMENTS}

This work was supported by the project SafeLand, 'Living with landslide risk in Europe: Assessment, effects of global change, and risk management strategies', under Grant Agreement No. 226479; by the project Wandland, 'Effects of wetting and drying cycles on landslide activity', under Grant Agreement No. 323 PERG06-GA-2009-256426 in the 7th Framework Programme of the European Commission; and by the Swiss Competence Centre Environment and Sustainability of the ETH Domain (CCES) (TRAMM project). This support is gratefully acknowledged.

\section{REFERENCES}

Airò Farulla, C. \& Ferrari, A. (2005). Controlled suction oedometric tests: analysis of some experimental aspects. Proceedings of an international symposium on advanced experimental unsaturated soil mechanics (eds A. Tarantino, E. Romero and Y. J. Cui), pp. 43-48. London, UK: Taylor \& Francis Group.

Bilotta, E., Cascini, L., Foresta, V. \& Sorbino, G. (2005). Geotechnical characterization of pyroclastic soils involved in huge flowslides. J. Geotech. Geol. Engng 23, No. 4, 365-402.

Bilotta, E., Foresta, V. \& Migliaro, G. (2006). Suction controlled laboratory tests on undisturbed pyroclastic soil: Stiffnesses and volumetric deformations. Proceedings of the 4th international conference on unsaturated soils (UNSAT 2006), Carefree, AZ, USA, pp. 849-860.

Brooks, R. H. \& Corey, A. T. (1964). Hydraulic properties of porous media, Hydrology Papers 3. Fort Collins, CO, USA: Colorado State University.

Cascini, L., Cuomo, S. \& Guida, D. (2008). Typical source areas of May 1998 flow-like mass movements in the Campania region, Southern Italy. Engng Geol. 96, No. 3-4, 107-125.

Cascini, L., Cuomo, S., Pastor, M. \& Sorbino, G. (2010). Modeling of rainfall-induced shallow landslides of the flow-type. J. Geotech. Geoenviron. Engng, ASCE 136, No. 1, 85-98.

Collins, K. \& McGown, A. (1974). The form and function of micro fabric in a variety of natural soils. Géotechnique 24, No. 2, 223-254, http://dx.doi.org/10.1680/geot.1974.24.2.223.

Crosta, G. B. \& Dal Negro, P. (2003). Observations and modeling of soil slip-debris flow initiation processes in pyroclastic deposits: the Sarno 1998 event. Nat. Hazards Earth Syst. Sci. 3, No. 1-2, $53-69$.

Damiano, E., Olivares, L. \& Picarelli, L. (2012). Steep-slope monitoring in unsaturated pyroclastic soils. Engng Geol. 137138, $1-12$

Eichenberger, J., Ferrari, A. \& Laloui, L. (2013). Early warning thresholds for partially saturated slopes in volcanic ashes. Comput. Geotech. 49, April, 79-89.

Ferrari, A., Eichenberger, J., Fern, J., Ebeling, P. \& Laloui, L. (2012). Experimental and numerical analysis of an unsaturated volcanic ash deposit for the establishment of an early warning system in a quarry in Costa Rica. Proceedings of Geocongress 2012: State of the art and practice in geotechnical engineering (eds R. D. Hryciw, A. Athanasopoulos-Zekkos, N. Yesiller, K. Rollins and D. Zekkos), Geotechnical Special Publication No. 225, pp. 2512-2521. Reston, VA, USA: ASCE.

Hujeux, J. (1979). Calcul numérique de problèmes de consolidation élastoplastique. $\mathrm{PhD}$ thesis, Ecole Centrale Paris, France.

Kunze, R. J. \& Kirkham, D. (1962). Simplified accounting for membrane impedance in capillary conductivity determinations. Soil Sci. Soc. Am. J. 26, No. 5, 421-426.

Leamy, M. L. (1984). Andisols of the world. Congresco international 
de suelos volcanicos. Ser. Inf. 13, pp. 368-387. La Laguna, Spain: Univ. de La Laguna, Secretariado de Publicaciones.

Leong, E. C., He, L. \& Rahardjo, H. (2002). Factors affecting the filter paper method for total matric suction measurements. Geotech. Test. J. 25, No. 3, 321-332.

Ng, C. \& Chiu, A. (2001). Behavior of a loosely compacted unsaturated volcanic soil. J. Geotech. Geoenviron. Engng 127, No. 12, 1027-1036.

Nuth, M. \& Laloui, L. (2007). New insight into the unified hydromechanical constitutive modelling of unsaturated soils. In Proceedings of the 3rd Asian conference on unsaturated soils (UNSAT-Asia), (eds Z. Z. Yin, Y. P. Yuan and A. C. F. Chiu), pp. 109-25. Nanjing, China: Science Press.

Nuth, M. \& Laloui, L. (2008). Effective stress concept in unsaturated soils: clarification and validation of a unified framework. Int. J. Numer. Anal. Methods Geomech. 32, No. 7, 771-801.

Olivares, L. \& Damiano, E. (2007). Postfailure mechanics of landslides: laboratory investigation of flowslides in pyroclastic soils. J. Geotech. Geoenviron. Engng 133, No. 1, 51-62.

Olivares, L. \& Picarelli, L. (2003). Shallow flowslides triggered by intense rainfalls on natural slopes covered by loose unsaturated pyroclastic soils. Géotechnique 53, No. 2, 283-287, http:// dx.doi.org/10.1680/geot.2003.53.2.283.
Picarelli, L., Olivares, L., Comegna, L. \& Damiano, E. (2008). Mechanical aspects of flow-like movements in granular and fine grained soils. Rock Mech. Rock Engng 41, No. 1, 179-197.

Romero, E., Gens, A. \& Lloret, A. (1999). Water permeability, water retention and microstructure of unsaturated Boom clay. Engng Geol. 54, No. 1, 117-127.

Romero, E., Alonso, E. E. \& Knobelsdorf, J. (2002). GMT/IR 0106. Laboratory tests on compacted sand-bentonite buffer material for the GMT emplacement project, NAGRA Project Report 02-05. Wettingen, Switzerland: NAGRA.

Salager, S., Nuth, M., Ferrari, A. \& Laloui, L. (2013). Investigation into water retention behaviour of deformable soils. Can. Geotech. J. 50, No. 2, 200-208.

Sorbino, G. \& Foresta, V. (2002). Unsaturated hydraulic characteristics of pyroclastic soils. Proceedings of the 3rd international conference on unsaturated soils, vol. 1, pp. 405-410. Rotterdam, the Netherlands: Balkema.

USAID (1998). US Agency for International Development Fact Sheet \#17. Washington, DC, USA: US Agency for International Development.

van Genuchten, M. T. (1980). A closed-form equation for predicting the hydraulic conductivity of unsaturated soil. Soil Sci. Soc. Am. J. 44, No. 5, 892-898. 